\title{
Impact of Plant Utilization on Irreversible Investment Under Uncertainty with Application to Refinery Investment
}

\author{
S. E. Omosigho ${ }^{1, *}$, Esosa Enoyoze ${ }^{2}$ and V. U. Ekhosuehi ${ }^{3}$ \\ ${ }^{1}$ Department of Mathematics, University of Benin, Benin City, Nigeria \\ E-mail: 〈seomosigho@uniben.edu〉 \\ 2 Department of Mathematics/ICT, Edo State University, Uzairue, Edo State, Nigeria \\ E-mail: 〈enoyoze.esosa@edouniversity.edu.ng \\ 3 Department of Statistics, University of Benin, Benin City, Nigeria \\ E-mail: 〈virtue.ekhosuehi@uniben.edu〉
}

\begin{abstract}
Why are some regions preferred when investors consider irreversible investment? This study offers an explanation to this question and suggests improvements that will assist disadvantaged regions improve on their bid for funds. The paper considers irreversible investment under uncertainty when installed capacity utilization is incorporated. We develop a normative model for irreversible investment problem under uncertainty using real options approach. Capacity utilization was not a major consideration by previous authors who assumed that installed capacity would be fully utilized. Variations in capacity utilization may be attributed to disruption in input supply or infrastructural bottlenecks that limit firms to get their products to customers. This study modifies the geometric Brownian motion for the value of a project to account for capacity utilization in the derivation of irreversible investment decision rule. The proposed model provides a theoretical explanation of how utilization affects irreversible investment decisions. Data on petroleum refinery margins is used to illustrate application of the proposed model to refinery investment. The study reveals that capacity utilization has an inverse effect on the investment trigger, and so, links irreversible investment decisions to plant utilization. We recommend optimal utilization of installed plant capacity for regions seeking funds for irreversible investment.
\end{abstract}

Keywords: geometric Brownian motion, irreversible investment, plant capacity utilization, petroleum refinery investment, real options

Received: June 11, 2020; accepted: March 03, 2021; available online: June 29, 2021

DOI: $10.17535 /$ crorr.2021.0005

\section{Introduction}

This paper considers the following irreversible investment problem: an investor or a firm is willing to invest in a single production plant. At any time, the firm has to decide whether to invest in the plant or postpone the investment. Once the investment is initiated, it is irreversible, but the decision to postpone the investment can be reversed. Further, the application of the installed capacity cannot be changed from the original purpose. The firm receives a stream of revenue after the plant is installed. The cost of the investment is known but the financial inflow after the installation is a stochastic process. The plant may not operate at installed capacity due to economic and environmental factors. We study the impact of plant utilization on the decision rule for the irreversible investment problem under uncertainty.

${ }^{*}$ Corresponding author. 
Our main inspiration for this study emanates from empirical evidence that some regions find it difficult to finance irreversible investment in production plants. For example, OPEC report [22] states that "Other Asia-Pacific region" remains dominant in additions to refinery capacity and that Africa will continue to depend on imports to meet her petroleum requirements. The question is why is there a dearth of investment in refineries in Africa? The OPEC report notes that in Africa the challenge in establishing new refineries is "how to finance and convert project ideas into actually building and operating facilities" [22, pp 165]. This OPEC report is the motivation for this study. We develop a normative model for irreversible investment under uncertainty using the real options approach. It is known that the traditional net present value (NPV) method is not applicable to irreversible investment under uncertainty because the traditional net present value method ignores both uncertainty and the concept of irreversibility $[15,25]$. The NPV of a project is the difference between the present value of revenue and the present value of operational cost.

The aim of this study is to develop a real options decision model for irreversible investment problem under uncertainty and installed capacity utilization. The study offers an explanation of why some countries are preferred by investors when considering irreversible investment. The main contribution of this paper is the inclusion of plant utilization in the development of a real options model for irreversible investment under uncertainty. Previous authors assumed that installed capacity would be utilized subject to demand. Variations in capacity utilization are encountered in practice and the inclusion of capacity utilization improves on the decision rule for irreversible investment. The main result is that capacity utilization has an inverse effect on the investment trigger.

The rest of this paper is organised as follows. Section 2 reviews the relevant literature on the subject. In Section 3, we shall consider plant capacity utilization. In Section 4, we present the model which includes capacity utilization in irreversible investment decision problems. $\mathrm{Nu}-$ merical illustration of the impact of utilization on refinery investment is presented in Section 5. Discussion and further investigation and conclusion are in Sections 6 and 7, respectively.

\section{Literature Review}

McDonald and Siegel [15] derive the decision rule for deciding when to invest in a production plant under uncertainty with the assumption that the present value of the plant $V_{t}$ follows a geometric Brownian motion or the present value of benefits follows Brownian motion with a jump. The decision rule has the form: invest now if $V_{t}$ is at or above a critical threshold $V^{*}$, otherwise, wait (see also [7]). The approach developed in [15] has been adopted in numerous studies where the value of the project follows stochastic processes other than the geometric Brownian motion (for example, $[3,4,9,11,19]$ ).

The use of Cox-Ingersoll - Ross model for the stochastic process governing the value of a firm is proposed in [9]. They argued that the Cox-Ingersoll-Ross model is more applicable compared to other mean reverting processes which were earlier proposed as alternatives to the geometric Brownian motion. [9] states that the Cox-Ingersoll -Ross process "guarantees a positive project value and has a constant mean reversion speed". Thijssen [29] proposes the use of spectrally negative Lĕvy jump-diffusion as a model for the value of a firm. Our observation is that no single stochastic process can be used for all irreversible investment projects. Furthermore, the geometric Brownian motion is still widely used in real options models because it provides a framework for obtaining mathematically tractable results and these are supported by empirical evidence.

The literature on real options approach has been reviewed by several authors such as $[8$, 14, 25]. None of the authors included utilization in their model. Svensson [28] discussed the bad news principles using data from a survey of firms in Uganda, see also [1]. The bad news 
principle emphasizes the importance of bad news in the decision to invest now or postpone the investment. The present paper provides a framework for capturing news on plant utilization.

The investment cost determines the plant capacity except in cases where the capacity of the plant is also a decision variable. Optimal choice of capacity has been examined by some authors using real options theory. Such authors study the issue of optimal timing of investment and optimal capacity choice. Dangl [5] examines the problem of investment timing and optimal choice of capacity. Citing examples such as hydro power plants and hotels, [5] argues that production capacity is fixed after the project is installed. The timing of investment and sizing of interconnection capacity in electricity transmission companies is discussed in [26]. Other authors considered optimal choice of capacity but allowed for output flexibility. Hagspiel et al. [10] examine investment timing and optimal choice of capacity for a firm contemplating irreversible investment under demand uncertainty subject to volume flexibility. They considered two cases of volume flexibility, viz., flexible capacity and inflexible capacity. Under flexible capacity a firm can adjust production output over time at no significant cost with the installed capacity level as the upper bound, while under inflexible capacity, the production capacity is fixed at installation. [6] studied the same problem but introduced two types of volume flexibility, namely downside volume flexibility and upside volume flexibility. The downside flexibility is similar to the flexible capacity of [10] but the upside flexibility allows the firm to produce beyond the installed capacity. [12, 13] also consider optimal investment timing and capacity decisions using the real options framework. In these papers dealing with flexible capacity, the main driving force is uncertainty in demand. There are instances where the analysis should be taken further. For instance, in developing countries, capacity utilization is a major consideration in the decision to invest. Capacity utilization is an indication of the weakness of the production infrastructure. In Nigeria, low refinery utilization has been attributed to the following reasons: lack of crude petroleum, failure of petroleum pipe lines, inadequate maintenance of refineries and power failure $[17,18]$. In the electricity industry in Nigeria, factors such as gas supply shortages, transmission constraints, and limited distribution networks are responsible for low utilization of installed power generation [16]. In contrast to the main driving force in the literature, this study takes up the irreversible investment decision problem by considering capacity utilization, which is not demand driven, but driven by economic and environmental factors. For example, it can happen in developing countries that a thermal electricity plant may not have sufficient gas to generate electricity and so, the plant is compelled to operate below the installed capacity even though the demand for electricity has not decreased. This study assumes that installed capacity at the point of entry is dictated by demand, technology and sunk cost. However, after the installation, economic and environmental factors can force a firm to operate below installed capacity. From the literature available to us, the effect of plant utilization, which may be due to economic and environmental factors, has not been considered in irreversible investment under uncertainty.

A recent work addresses the long-run dynamics of generation capacity for power plant as an irreversible investment problem under uncertainty using real options analysis [24]. In agreement with this new trend of investment decision-making under irreversibility and uncertainty, the present study is apt for including plant capacity utilization. Nonetheless, the way the capacity mechanism is figured out in this study is quite different from that of [24], where capacity is viewed as an incentive. Thus, capacity was defined to be either price-based capacity or quantitybased remuneration capacity. This is not the case herein as capacity is seen from both economic and environmental perspectives which characterize developing countries.

In the refinery industry, empirical evidence shows that the nameplate capacity (installed capacity) of a plant is underutilized in some regions (see Table 1). Table 1, which shows crude unit utilization in refineries in different regions according to [22], indicates that Africa has the lowest utilization rate. We are not aware of any research on irreversible investment-plant capacity utilization problem under uncertainty. In this sense, this study contributes to the 
Table 1: Crude unit utilizations (\% of calendar day capacity)

\begin{tabular}{|cccccccccc|}
\hline Year & World & $\begin{array}{c}\text { US \& } \\
\text { Canada }\end{array}$ & $\begin{array}{c}\text { Latin } \\
\text { America }\end{array}$ & Africa & Europe & $\begin{array}{c}\text { Russia\& } \\
\text { Caspian }\end{array}$ & $\begin{array}{c}\text { Middle } \\
\text { East }\end{array}$ & $\begin{array}{c}\text { China } \\
\text { Other } \\
\text { Asia } \\
\text { Pacific }\end{array}$ \\
\hline \hline 2018 & 81.7 & 89.9 & 55.8 & 54.8 & 75.1 & 96.7 & 81.1 & 81.5 & 90.6 \\
2020 & 80.4 & 88.8 & 61.1 & 65.0 & 78.9 & 88.6 & 77.5 & 73.6 & 88.3 \\
2025 & 80.6 & 88.7 & 67.5 & 64.7 & 79.7 & 87.4 & 77.9 & 75.7 & 85.1 \\
2030 & 79.4 & 86.7 & 71.9 & 62.5 & 76.4 & 85.3 & 78.4 & 77.2 & 82.1 \\
2035 & 78.4 & 83.1 & 73.8 & 65.8 & 73.7 & 82.5 & 80.6 & 77.4 & 80.7 \\
2040 & 77.4 & 78.2 & 78.4 & 68.9 & 69.3 & 81.2 & 81.2 & 78.3 & 79.9 \\
\hline
\end{tabular}

Source: [22] World Oil Outlook 2040 page 171

literature on irreversible investment under uncertainty. The model proposed in this paper offers rational explanations for the observation in [22] that Asian countries are the preferred destination for refinery investment.

\section{Capacity Utilization}

Once a firm pays a sunk cost for an irreversible investment project, it receives an installed capacity. We assume that the firm can only produce output up to the installed capacity and define capacity utilization as output divided by installed capacity, i.e.

$$
\text { Capacity utilization, } U=\frac{\text { Plant Output }}{\text { Plant Installed Capacity }}, 0<U \leq 1
$$

In Table 1, some regions have high utilization rates and others have low utilization rates. Omosigho [21] discussed the utilization of power generating plants in Nigeria and states that the utilization is 0.69 in the period studied. Okunade [20] considers capacity utilization in Nigeria's manufacturing sector and concludes that production "capacity was grossly under utilised in virtually every productive firm in Nigeria" based on data on capacity utilization from 1981 to 2016. Some reasons for low capacity utilization in Nigeria include lack of raw materials and inability to move finished products outside the production factory. These factors affect the product supply side and the sales side for a production firm and are clearly not demand dependent. Demand forecast ignores such exogenous economic and environmental factors.

In the classical real options approach for developing irreversible investment decisions, plant utilization is ignored. Nevertheless, when the capacity of a firm is underutilized, the volatility of the value of the firm is affected. This is due to the fact that the volume of output can easily fluctuate. In this paper, we develop a model that include plant utilization in irreversible investment under uncertainty.

\section{The Model including Utilization}

We derive the investment decision rule for a firm willing to pay a sunk cost $I$ at any time $\mathrm{t}$ for a project with a present value $V_{t}$. The value of the project acquired is affected by plant utilization $U$ and uncertainty in demand. We define $\omega=1 / U$.

\section{Axiom 1}

The value of the project follows a geometric Brownian motion of the form:

$$
d V=\alpha(V) d t+\omega \sigma(V) d z
$$

where $\alpha(V)$ and $\sigma(V)$ are the drift and volatility of the value of the project when the plant operates at the installed capacity, $d z$ is a Wiener increment, $1 \leq \omega<\infty$ is a constant defined 
by the average capacity utilization of the plant. When $\omega=1$, the plant operates at its installed capacity. This is the ideal situation. In what follows, we take $\alpha(V)=\alpha>0$ and $\sigma(V)=\sigma>0$.

\section{Axiom 2.}

We assume that the project produces a profit Margin $M_{t}$ that follows the geometric Brownian process:

$$
d M=\alpha M d t+\omega \sigma M d z
$$

These assumptions may not cover all conceivable cases, but they do give rise to well posed irreversible investment problem with tractable optimal solution and useful corollaries. A property of the geometric Brownian process is that the expected value of the margin is $E\left[M_{t}\right]=M_{0} e^{\alpha t}$, where $M_{0}$ is the initial value.

Proposition 1. Let $M_{t}$ be the profit margin of the project. The value of the project $V_{t}$ is given by

$$
V_{t}=M_{0} /(\rho-\alpha)
$$

where $\rho$ is the discount rate and $\rho>\alpha$.

Proof. The value of the project is the expected value of the margins discounted at the rate $\rho>\alpha$. Hence

$$
V_{t}=\int_{0}^{\infty} M_{0} \exp (\alpha s) \exp (-\rho s) d s=M_{0} /(\rho-\alpha)
$$

The exponential function, $\exp (-\rho t)$, models the discounted present value of the expected margin stream. A similar proof is in [7].

At any time $t$, the firm can invest in the project or postpone the investment. The value of the option to invest at time $t$ is $F(V)$. The optimal stopping problem is:

$$
F(V)=\max \left\{E\left[\left(V_{\tau}-I\right) \exp (-\rho \tau)\right] ; V_{0}=V\right\}
$$

where $\tau$ is the time of investment and $E$ is the expectation function. Using the Bellman equation and Ito's lemma, we have

$$
0.5 \omega^{2} \sigma^{2} V^{2} F^{\prime \prime}(V)+\alpha V F^{\prime}(V)-\rho F(V)=0
$$

The boundary conditions are:

$$
\begin{gathered}
F(0)=0 \\
F\left(V^{*}\right)=V^{*}-I \\
F^{\prime}\left(V^{*}\right)=1
\end{gathered}
$$

The generator in this case is

$$
L_{V}(F)=0.5 \omega^{2} \sigma^{2} V^{2} F^{\prime \prime}(V)+\alpha V F^{\prime}(V)-\rho F(V)
$$

The solution of the second order ODE in (6) has the form $F(V)=A V^{\beta} . L_{V}(F)=0$ leads to

$$
0.5 \omega^{2} \sigma^{2} V^{2} \beta(\beta-1) A V^{\beta-2}+\alpha V \beta A V^{\beta-1}-\rho A V^{\beta}=0
$$

which reduces to

$$
0.5 \omega^{2} \sigma^{2} \beta(\beta-1)+\alpha \beta-\rho=0
$$

with two roots for $\beta$ namely:

$$
\beta_{1}=\left(\frac{1}{2}-\frac{\alpha}{\omega^{2} \sigma^{2}}\right)+\sqrt{\left(\frac{1}{2}-\frac{\alpha}{\omega^{2} \sigma^{2}}\right)^{2}+\frac{2 \rho}{\omega^{2} \sigma^{2}}}>1
$$


and

$$
\beta_{2}=\left(\frac{1}{2}-\frac{\alpha}{\omega^{2} \sigma^{2}}\right)-\sqrt{\left(\frac{1}{2}-\frac{\alpha}{\omega^{2} \sigma^{2}}\right)^{2}+\frac{2 \rho}{\omega^{2} \sigma^{2}}}<0
$$

$\beta_{1}>1$ and $\beta_{2}<0$ follows from the properties of the quadratic equation in (12) as explained below. To satisfy the boundary condition in equation (7), the general solution to (6) which has the form

$$
F(V)=A V^{\beta_{1}}+B V^{\beta_{2}}
$$

must have $B=0$. So the solution of (6) subject to $F(0)=0$ is $F(V)=A V^{\beta_{1}}$. In what follows, we set $\beta=\beta_{1}$. Using the boundary conditions (8) and (9), we have:

$$
V^{*}=\beta I /(\beta-1)
$$

and

$$
A=\beta^{-1}(\beta I /(\beta-1))^{1-\beta}
$$

Equation (16) can be re-written as:

$$
M^{*}=\beta I(\rho-\alpha) /(\beta-1)
$$

in terms of margins using equation (4). The decision rule is that the firm should invest at time $t$ if $M_{t}$ is at or above the critical threshold $M^{*}$, otherwise, the firm should wait. We shall consider the effect of plant utilization on the investment decision rule prescribed by (18).

The characteristic quadratic equation when utilization is incorporated into the stochastic process is

$$
Q(\beta)=\frac{1}{2} \omega^{2} \sigma^{2} \beta(\beta-1)+\alpha \beta-\rho
$$

Since the coefficient of $\beta^{2}$ in (19) is positive, the graph of $Q(\beta)$ against $\beta$ will be $\mathrm{U}$ - shaped upward pointing parabola tending to $+\infty$, as $\beta \rightarrow \pm \infty$. Furthermore, $Q(0)=-\rho<0$ and $Q(1)=\alpha-\rho<0$. Hence $Q(\beta)$ has two roots as shown earlier, one root $\beta_{1}>1$ and the other $\operatorname{root} \beta_{2}<0$. In our analysis, only $\beta=\beta_{1}>1$, is relevant. Equations (12 and 13) show the presence of $\omega$, the reciprocal of plant utilization, which to the best of our knowledge was not considered in previous real options models or literature.

It is known that if $f$ is a differentiable function of a single real variable then $f^{\prime}(a)>0$ implies $f$ is increasing at $a$ and $f^{\prime}(a)<0$ implies $f$ is decreasing at $a$. Further, if $z=f(x, y)$ is a function of two real variables then the total derivative of the function is given by:

$$
d z=\frac{\partial z}{\partial x} d x+\frac{\partial z}{\partial y} d y
$$

Proposition 2. As capacity utilization $U$ decreases, the value of $\omega$ increases and there is an increase in the value of $\beta /(\beta-1)$.

Proof. We examine how $\beta /(\beta-1)$ changes as the utilization, $U$, changes. We use the quadratic $Q(\beta)$ given in equation (19) for the analysis. From the fundamental quadratic equation:

$$
Q(\beta)=\frac{1}{2} \omega^{2} \sigma^{2} \beta(\beta-1)+\alpha \beta-\rho=0
$$

We have

$$
\begin{gathered}
\frac{\partial Q}{\partial \beta} \frac{\partial \beta}{\partial \omega}+\frac{\partial Q}{\partial \omega}=0 \\
\frac{\partial Q}{\partial \beta}=(\omega \sigma)^{2}\left(\beta-\frac{1}{2}\right)+\alpha
\end{gathered}
$$


At $\beta>1, \frac{\partial Q}{\partial \beta}>0$.

$$
\frac{\partial Q}{\partial \omega}=\sigma^{2} \omega \beta(\beta-1)
$$

At $\beta>1, \frac{\partial Q}{\partial \omega}>0$. From equation (22) we conclude that $\frac{\partial \beta}{\partial \omega}<0$. This means that as $\omega$ increases, $\beta$ decreases and in particular $\beta /(\beta-1)$ increases. So a decrease in the capacity utilization $U$ causes an increase in $\omega$ and a corresponding increase in the value of $\beta /(\beta-1)$.

From proposition 2, we deduce the following:

1. As the rate of utilization $U$ decreases, $\omega$ increases and $\beta /(\beta-1)$ increases.

2. As the rate of utilization $U$ increases, $\omega$ decreases and $\beta /(\beta-1)$ decreases.

3. If the rate of utilization $U=1$ then $\omega=1$ and we have the same result as in [7].

Ideally the project with a lower value of $\beta /(\beta-1)$ will be preferred to a project with a higher value of $\beta /(\beta-1)$. Thus, utilization has a profound effect on the investment trigger all things being equal.

\section{Numerical Illustration}

We shall use the refinery margins published in [2]. The margins considered are for the US Gulf Coast (USGC), North West Europe (NWE) and Singapore Medium Sour Hydrocracking (SMSH). The data set is for $2000-2018$. First, we present a cursory review of the theory we shall use to verify if the margins follow a geometric Brownian motion.

Proposition 3. [30]. Let $\left\{M_{t}\right\}, t=0,1,2, \ldots, n$ be $n+1$ observations from a geometric Brownian motion. If $r_{t}=\ln \left(M_{t} / M_{t-1}\right), t=1,2,3, \ldots, n$, then $r_{t}$ are independent and normally distributed.

The procedure for verifying that the stochastic process for the margins is a geometric Brownian motion is as follows [30]. Let $M_{0}, M_{1}, \ldots, M_{n-1}, M_{n}$ be a set of $n+1$ empirical annual values of refinery margins. Set $r_{t}=\ln \left(M_{t} / M_{t-1}\right), t=1,2, \ldots, n$. We test that $r_{t}$ are independent and normally distributed. The Shapiro-Wilk test $[23,27]$ is a suitable test for both hypotheses. We use the SPSS Shapiro-Wilk test to do the analysis of the $r_{t}$ values for the three refinery margins annual data set. For each set of data, eighteen (18) annual values were derived. Results of the

Table 2: Tests for normality and independence.

\begin{tabular}{|c|c|c|c|}
\hline \multirow[b]{2}{*}{$r_{t}$ Values } & \multicolumn{3}{|c|}{ Shapiro-Wilk } \\
\hline & W Statistic & $\mathrm{df}$ & P-Value. \\
\hline USGC $r_{t}$ Values & 0.968 & 18 & 0.763 \\
\hline NWE $r_{t}$ Values & 0.965 & 18 & 0.701 \\
\hline SMSH $r_{t}$ Values & 0.848 & 18 & 0.008 \\
\hline
\end{tabular}

Shapiro-Wilk tests for the $\left\{r_{t}\right\}$ values of the margins for USGC, NWE and SMSH are shown in Table 2. The results show that the $\left\{r_{t}\right\}$ values of the margins for USGC and NWE have normal distribution $(p-$ value $>0.05)$ while the $\left\{r_{t}\right\}$ values of the margins for SMSH cannot be described by a normal distribution $(p-$ value $<0.05)$. This means that the margins for NWE and USGC follow a geometric Brownian motion while the margins for SMSH do not follow a geometric Brownian motion.

We now proceed to estimate the parameters of the geometric Brownian motion for the margins for NWE, and USGC following [30, pp229]. If $\bar{r}=\sum_{t=1}^{n} \frac{r_{t}}{n}$ and $s^{2}=\sum_{t=1}^{n} \frac{\left(r_{t}-\bar{r}\right)^{2}}{(n-1)}$ then estimators for the parameters of the geometric Brownian motion are given by $\alpha=\bar{r}+0.5 s^{2}$ and $\sigma=s$. Table 3 shows $\bar{r}, s^{2}, \alpha$ and $\sigma$ for the two margins. 
Table 3: Values of parameters

\begin{tabular}{|cll|}
\hline Parameter & NWE & USGC \\
\hline \hline $\bar{r}$ & 0.01715 & 0.0351157 \\
$s^{2}$ & 0.259 & 0.187 \\
$\alpha$ & 0.14665 & 0.12861 \\
$\sigma$ & 0.508920426 & 0.432434966 \\
\hline
\end{tabular}

Table 4: Values of $\beta /(\beta-1)$ for all regions including the ideal case $(\omega=1)$ and for both $N W E$ and USGC margins

\begin{tabular}{|c|c|c|c|c|c|c|c|}
\hline & $\alpha$ & $\bar{U}$ & $\omega$ & $\sigma$ & $\rho$ & $\beta /(\beta-1)$ & Regions \\
\hline \multirow[t]{10}{*}{ NWE } & 0.14667 & 81.7 & 1.22399 & 0.50892 & 0.175 & 1313.56105 & "World \\
\hline & 0.14667 & 89.9 & 1.112347 & 0.50892 & 0.175 & 12.32388 & US/CANADA \\
\hline & 0.14667 & 55.8 & 1.792115 & 0.50892 & 0.175 & 21.55708 & Latin America \\
\hline & 0.14667 & 54.8 & 1.824818 & 0.50892 & 0.175 & 22.10448 & Africa \\
\hline & 0.14667 & 75.1 & 1.331558 & 0.50892 & 0.175 & 14.85643 & EUROPE \\
\hline & 0.14667 & 96.7 & 1.034126 & 0.50892 & 0.175 & 11.52208 & Russia \\
\hline & 0.14667 & 81.1 & 1.233046 & 0.50892 & 0.175 & 13.66618 & Middle East \\
\hline & 0.14667 & 81.5 & 1.226994 & 0.50892 & 0.175 & 13.59584 & China \\
\hline & 0.14667 & 90.6 & 1.103753 & 0.50892 & 0.175 & 12.23317 & Other Asia Pacific \\
\hline & 0.14667 & 100 & 1 & 0.50892 & 0.175 & 11.18905 & Ideal Case \\
\hline \multirow[t]{10}{*}{ USGC } & 0.12866 & 81.7 & 1.22399 & 0.43243 & 0.175 & 7.27318 & Thorld \\
\hline & 0.12866 & 89.9 & 1.112347 & 0.43243 & 0.175 & 6.70339 & US/CANADA \\
\hline & 0.12866 & 55.8 & 1.792115 & 0.43243 & 0.175 & 10.89930 & Latin America \\
\hline & 0.12866 & 54.8 & 1.824818 & 0.43243 & 0.175 & 11.14534 & Africa \\
\hline & 0.12866 & 75.1 & 1.331558 & 0.43243 & 0.175 & 7.86634 & EUROPE \\
\hline & 0.12866 & 96.7 & 1.034126 & 0.43243 & 0.175 & 6.33198 & Russia \\
\hline & 0.12866 & 81.1 & 1.233046 & 0.43243 & 0.175 & 7.32145 & Middle East \\
\hline & 0.12866 & 81.5 & 1.226994 & 0.43243 & 0.175 & 7.28916 & China \\
\hline & 0.12866 & 90.6 & 1.103753 & 0.43243 & 0.175 & 6.66146 & Other Asia Pacific \\
\hline & 0.12866 & 100 & 1 & 0.43243 & 0.175 & 6.17714 & Ideal Case \\
\hline
\end{tabular}

Table 5: Values of $\beta /(\beta-1)$ for selected Regions and for both NWE and USGC margins

\begin{tabular}{|lccc|}
\hline Region & Utilization & $\beta /(\beta-1)$ & $\beta /(\beta-1)$ \\
& & NWE & USGC \\
\hline \hline Other Asia Pacific & 90.6 & 12.23317 & 6.66146 \\
China & 81.5 & 13.59584 & 7.28916 \\
Middle East & 81.1 & 13.66618 & 7.32145 \\
Latin America & 55.8 & 21.55708 & 10.89930 \\
Africa & 54.8 & 22.10448 & 11.14534 \\
\hline
\end{tabular}

In the sequel, we take $\rho=0.175$. The investment rule is to invest when the margin is greater or equal to $M^{*}=\frac{\beta(\rho-\alpha) I}{(\beta-1)}$. Since $(\rho-\alpha) I$ is a constant, we shall examine the effect of utilization on $\beta /(\beta-1)$. Table 4 shows the values of $\beta /(\beta-1)$ for the different regions for the margins NWE and USGC using the OPEC utilization data for 2018. The regions mostly in need of refineries are Africa, Other Asia Pacific, China, and Latin America. Table 5 shows $\beta /(\beta-1)$ values for these regions for the two margins. 


\section{Discussion and further investigation}

Among the regions, Asia has the least value of $\beta /(\beta-1)$ and so it is the most attractive for irreversible investment. Africa with the highest value of $\beta /(\beta-1)$ is the least attractive for irreversible investment. The ideal case, $\omega=1$, has the lowest value of $\beta /(\beta-1)$. This also illustrates the impact of ignoring capacity utilization on the investment trigger. From the foregoing results, we conclude that capacity utilization, $\mathrm{U}$, has an inverse effect on the investment trigger, $\beta /(\beta-1)$. Further, the results show that African countries will find it difficult to attract funds for investment in refineries and hence they will continue to import petroleum products. This is in line with the observation by OPEC that although Africa has plans for the establishment of refinery, she cannot find investors willing to finance her refinery projects. African countries must improve on the utilization of their installed capacity if they are to attract funds.

The results in this paper could serve as a handy tool for prospective investors when the margin follows a geometric Brownian motion. One of the margins we investigated did not follow a geometric Brownian motion. It is possible to develop a semi-parametric model for the investment problem and include utilization. One approach is to estimate the cost incurred due to the effect of capacity utilization separately and then add the estimated cost to the sunk cost for the project when taking decisions on irreversible investment under uncertainty. In this regard, the cost incurred due to the effect of capacity utilization in one year is first estimated.

Let $H$ be the annual cost incurred when there is no production. Let $C(U)$ be the cost associated with the utilization level $U$. Then

$$
\frac{d C(U)}{d U}=-H ; \quad C(1)=0
$$

$U$ is the plant utilization for the year. $C(1)=0$ means no cost is incurred when utilization of installed capacity is 1 .

The solution to $(25)$ is $C(U)=(1-U) H$. This means that utilization cost is determined by unutilized capacity. If $u_{i}$ is the average plant utilization in year $i$ then the discounted total cost due to under utilization of installed capacity is given by

$$
I^{\prime}=\sum_{i=1}^{\infty} \frac{\left(1-u_{i}\right) H}{(1-\rho)^{i}}
$$

If $I$ is the sunk cost for the project, then the combined cost of having the plant is $I+I^{\prime}$. With the estimated cost due to utilization included in the overall cost of acquiring the plant, we can examine the effect of utilization on the investment decision process.

The next step is to derive the investment decision rule under the desired stochastic process without including utilization in the stochastic process for the value of the firm. For example if the stochastic process for the margin is a geometric Brownian motion, then $M^{*}$ is given by

$$
M^{*}=\frac{\beta_{3}}{\beta_{3}-1}(\rho-\alpha)\left[I+I^{\prime}\right]
$$

where

$$
\beta_{3}=\left(\frac{1}{2}-\frac{\alpha}{\sigma^{2}}\right)+\sqrt{\left(\frac{1}{2}-\frac{\alpha}{\sigma^{2}}\right)^{2}+\frac{2 \rho}{\sigma^{2}}}>1
$$

This approach can be used for any stochastic process and further investigation of this semiparametric model is worthwhile. 


\section{Conclusion}

This paper contributes to the development of decision models for irreversible investment under uncertainty by considering installed capacity utilization. Explicit relationship between utilization and irreversible investment trigger is derived in the paper. The impact of plant capacity utilization on the investment rules are demonstrated both theoretically and numerically. An inverse relationship is established between capacity utilization and the investment trigger if the value of the firm follows a geometric Brownian motion. Regions with low capacity utilization will not attract funds to finance their demand driven irreversible investment projects. In order to attract funds, such regions should find ways and means of increasing the utilization of existing facilities.

\section{References}

[1] Bernanke, B. S. (1983). Irreversibility, uncertainty, and cyclical investment. The Quartely Journal of Economics, 98(1), 85-106. doi: 10.2307/1885568

[2] BP Statistical Review of World Energy (2019). Table: Oil: Regional refining margins from 1992. https://www.bp.com/en/global/corporate/energy-economics/statistical-reviewof-world-energy.html

[3] Carmona, J. and Leŏn, A. (2007). Investment under CIR interest rate. Finance Research Letters, 4, 242-253.

[4] Cox, J. C., Ingersoll, J. E. and Ross, S. A. (1985). A theory of the term structure of interest rates. Econometrica, 53(2), 385-407. doi: 10.2307/1911242

[5] Dangl, T. (1999). Investment and capacity choice under uncertain demand. European Journal of Operational Research, 117(3), 415-428.

[6] De Giovanni, D. and Massabò, I. (2018). Capacity investment under uncertainty: The effect of volume flexibility. International Journal of Production Economics, 198, 165-176. doi: 10.1016/j.ijpe.2018.01.030

[7] Dixit, A. K. and Pindyck, R. S. (1994). Investment Under Uncertainty. New Jersey: Princeton University Press. https://press.princeton.edu/books/hardcover/9780691034102/investmentunder-uncertainty

[8] Enoyoze E. and Omosigho S. E. (2018). Real options in irreversible investment under uncertainty: a review. Croatian Operational Research Review, 9(1), 25-35. doi: 10.17535/crorr.2018.0003

[9] Ewald, C.-O. and Wang, W.-K.(2010). Irreversible investment with Cox-Ingersoll- Ross type mean reversion. Mathematical Social Sciences, 59(3), 314-318. doi: 10.1016/j.mathsocsci.2009.12.002

[10] Hagspiel, V., Huisman, K. J. M., and Kort, P. M. (2016). Volume flexibility and capacity investment under demand uncertainty. International Journal of Production Economics, 178, 95-108. doi: 10.1016/j.ijpe.2016.05.007

[11] Ingersoll, J. E., and Ross, S. A. (1992). Waiting to invest: investment and uncertainty. The Journal of Business, 65(1), 1-29. https://www.jstor.org/stable/2353172?seq=1

[12] Jeon, H. (2019). Investment timing and capacity decisions with time-to-build in a duopoly market. Electronic copy available at: https://ssrn.com/abstract $=3331490$

[13] Kozlova, M., Fleten, Stein-Erik and Hagspiel, V. (2020). Optimal timing and capacity choice under the rate-of-return renewable energy support. MethodsX, 7, 100828. doi: 10.1016/j.mex.2020.100828

[14] Liu, L., Zhang, M. and Zhao, Z. (2019). The application of real option to renewable energy investment: a review. Energy Procedia, 158, 3494-3499. doi: 10.1016/j.egypro.2019.01.921

[15] McDonald, R. and Siegel, D.(1986). The Value of Waiting to Invest. The Quarterly Journal of Economics, 101(4), 707-727. doi: 10.2307/1884175

[16] NERC (2019). Nigerian Electricity Regulatory Commission. Quarterly Report Third Quarter 2019. Available from http://www.nerc.gov.ng

[17] NNPC (2006). Nigerian National Petroleum Corporation. Annual Statistical Bulletin, (Web Version). Available from https://nnpcgroup.com

[18] NNPC (2017). Nigerian National Petroleum Corporation. Monthly Financial and Operations Report May 2017. Available from https://nnpcgroup.com 
[19] Nunes, C. and Pimentel, R. (2017). Analytical solution for an investment problem under uncertainties with shocks. European Journal of Operational Research, 259(3), 1054-1063. doi: 10.1016/j.ejor.2017.01.008

[20] Okunade, S.O. (2018). Effect of capacity utilisation on manufacturing firms production in Nigeria. Global Journal of Management and Business Research: B Economics and Commerce, 18(1), 29-38.

[21] Omosigho, I. (2019). Utilization of power generating plants in Nigeria. Journal of the Nigerian Association of Mathematical Physics, 49(1), 305-312. https://www.ajol.info/index.php/jonamp/article/view/196505

[22] OPEC (2019). 2019 OPEC World Oil Outlook 2040 Report. Available from http://www.opec.org

[23] Razali, N. M. and Wah, Y. B.(2011). Power comparisons of Shapiro-Wilk, Kolmogorov-Smirnov, Lilliefors and Anderson-Darling test. Journal of Statistical Modeling and Analytics, 2(1), 21-33.

[24] Rios-Festner, D., Blanco, G. and Olsina, F. (2020). Long-term assessment of power capacity incentives by modeling generation investment dynamics under irreversibility and uncertainty. Energy Policy, 137, 111185. doi: 10.1016/j.enpol.2019.111185

[25] Schachter, J. A. and Mancarella, P.(2016). A critical review of real options thinking for valuing investment flexibility in Smart Grids and low carbon energy systems. Renewable and Sustainable Energy Reviews, 56, 261-271. doi: 10.1016/j.rser.2015.11.071

[26] Sereno, L. and Efthimiadis, T. (2018). Capacity constraints, transmission investments, and incentive schemes. Energy Policy, 119, 8-27. doi: 10.1016/j.enpol.2018.04.004

[27] Shapiro, S. S. and Wilk, M. B. (1965). An Analysis of Variance Test for Normality (Complete Samples). Biometrika, 52(3/4), 591-611. doi: 10.2307/2333709

[28] Svensson, J. (2000). Is the bad news principle for real? Economics Letters, 66(3), 327-331. doi: 10.1016/S0165-1765(99)00205-0

[29] Thijssen, J. J. J. (2015). A model of irreversible investment with construction and revenue uncertainty. Journal of Economic Dynamics \& Control, 57, 250-266. doi: 10.1016/j.jedc.2015.06.001

[30] Tsay, R. S. (2002). Analysis of Financial Time Series. New York, United States of America: John Wiley and Sons, Inc. 